\title{
Painless aortic dissection with slurred speech (Neurologic symptom)
}

\author{
Esmaeal Rayat Dost ${ }^{1}$, Saeed Barazandehpour ${ }^{2}$, Navid Kalini ${ }^{3}$, Samaneh Abiri ${ }^{*}$ \\ 'Department of Emergency Medicine, Jahrom University of Medical sciences, Jahrom, Iran \\ 2Department of Emergency Medicine, Kerman University of Medical sciences, Kerman, Iran \\ ${ }^{3}$ Research center for social Determinants of Health, Jahrom University of Medical Sciences, Jahrom, Iran
}

\author{
Received: 26 January 2020 \\ Accepted: 17 May 2020 \\ Published online: 27 May 2020 \\ *Corresponding author: Samaneh \\ Abiri, Tel: 09173922398 , \\ Email:samaneh.abiri@gmail.com \\ Competing interests: None. \\ Funding information: All the \\ expenses of this research were paid \\ by the researchers. \\ Citation: Rayat Dost E, \\ Barazandehpour S, Kalini N, \\ Abiri S. Painless aortic dissection \\ with slurred speech (Neurologic \\ symptom). Journal of Emergency \\ Practice and Trauma 2021; 7(1): $71-$ \\ 73. doi: 10.34172/jept.2020.18.
}

\begin{abstract}
Introduction: Aortic dissection is an uncommon disorder with a high mortality rate, especially if misdiagnosis and mistreatment are not considered.

Case Presentation: We present a 67-year old female with slurred speech and left sided plegia during her brother's funeral. The patient did not have any chest pain. she was referred to our emergency department by emergency medicine service due to being suspicious of cerebrovascular accident (CVA) )as code 724). However, owing to low blood pressure and atypical symptoms of the patient, we did rapid ultrasound for shock and hypotension (RUSH) exam in the emergency department to detect aortic dissection. After doing the computed tomography (CT) angiography, the diagnosis of aortic dissection was confirmed. As the vascular surgeon was not present in our surgery department, we transferred the patient to Namazi hospital by air ambulance to undergo the surgery. She was discharged from hospital with complete recovery.

Conclusion: Aortic dissection symptoms can be manifested in different ways such as pulmonary embolism, acute coronary syndrome, and CVA. Therefore, clinicians must always have the differential diagnosis of aortic dissection in their mind and be aware of its various manifestations.
\end{abstract}

Keywords: Aortic dissection, CVA, Neurologic symptom, Cerebrovascular accident

\section{Introduction}

Aortic dissection is known to be an uncommon and serious disease in which the inner layers of aorta or other large vessels originating from heart tear (1). If the disease is not diagnosed quickly, the severity of tearing lesion would increase and causes more injuries and mortalities, especially if we have misdiagnosis or mistreatment (2).

\section{Case Presentation}

We present a 67-year old female who arrived at the emergency department of Peymanieh hospital due to decreased level of consciousness in her brother's funeral. Her chief complaints were difficulty in speech and inability to walk due to left sided weakness. In the present case, the patient did not mention any positive history related to aortic dissection. Her past medical history revealed hypertension, and the patient took losartan $25 \mathrm{mg}$ twice daily. Her daughter mentioned that she does not take her medication regularly. Social history was not significant. At the presentation time, the patient was ill. Her vital signs were: blood pressure $80 / 60$ in her both arms with a pulse rate of $70 / \mathrm{min}$, respiratory rate was $18 / \mathrm{min}$ with a temperature of 37 axillary. In addition, her pupil was normal and reactive to light. Jugular venous pressure was normal. The chest wall had symmetrical expansion with normal and clear breathing sound bilaterally. There was no deviation of trachea. The maximal pulse point was detected in the left fifth intercostal space, anterior axillary line. The cardiac physical examination revealed a regular rate and rhythm without muffled heart sounds; while there was a grade 3 of diastolic apical murmur. We did not observe paradoxical pulses. Also, the abdomen was soft without a visible and palpable pulsatile mass. Her extremities were cold but no cyanosis happened at extremities. There were symmetrical filiform pulses. No peripheral edema was reported. When arriving to the emergency department, she was orient to all three dimensions of time, place and person, but her speech was slurred. Muscle force was 3/5 in left side and 5/5 in right side. Deep Tendon Reflexes were scored $3 / 4$ and $2 / 4$, respectively in left and right side. Plantar Reflex was normal both sides. Other physical exams were normal. At the presentation time we faced 
impression of cerebrovascular accident (CVA) but because of hypotension with syncopal attack and presentation of neurological symptom, we decided to do rapid ultrasound for shock and hypotension (RUSH) exam at the bedside of the patient in the emergency room. Report of RUSH exam was normal except in pipe exam which is being conducted to evaluate the arterial aspect of the circulatory system. Pipe exam results were in favor of abdominal aortic dissection with aorta diameter of 3 centimeters. Also, as bedside ultrasound revealed some important information, additional imaging was requested. Computed tomography (CT) angiography of chest and abdomen was done and the diagnosis of thoracic and abdomen aortic dissection was confirmed. Due to blood pressure of $80 / 60$ and pulse rate of 70 , she did not need any hypertensive medication. We referred her to thoracic surgery department of Namazi hospital of Shiraz University of Medical Sciences by air ambulance. She had a successful emergency operation and completely recovered after the surgery. She was discharged within 30 days after the operation (Figure 1).

\section{Discussion}

Aortic dissection happens when a longitudinal cleavage takes place in the aortic media, caused by a dissecting column of blood (1). Aortic dissection is an uncommon disease with a high rate of mortality and morbidity. It is mostly seen in men at the age of $60-70$. It is uncommon at the age under 40. Pain seems to be the most common manifestation of aortic dissection as happens in $90 \%$ of cases. In this regard, chest pain is sharp and severe. The diagnostic criteria of aortic dissection are minimally understood. There are no definitive criteria due to wide range of symptoms as we can see in our case (1-3). Other manifestations of aortic dissection are syncope (with the incidence of $9 \%$ ) or functional neurological disorder (FND) (less common in old age; $18 \%$ in old against $28 \%$ in young age), aortic regurgitation, and hypotension $(1,4)$. Patients with aortic dissection and syncope have higher mortality rates. The risk factors of aortic dissection are age, chronic hypertension, Marfan syndrome, aortic atherosclerosis, and cocaine abuse (5-7). Our patient had both syncopal attack and FND (with higher mortality and rare presentation) (5-7). Aortic dissection has two types, namely A and B (type A has a higher mortality rate, about 22\%-31\%). Some cases of aortic dissection have manifestations similar to myocardial infarction (MI) and CVA. Thus, due to its similarity to other urgent diseases, if aortic dissection is misdiagnosed with MI or CVA, while having opposite treatment approaches, wrong treatment with fibrinolytic or anticoagulant can worsen the patient's condition. Diagnosis of aortic dissection should be regarded with suspicion and it should always be in mind of physicians as a potential differential diagnosis concerning MI and CVA. Physicians ought to be aware that the exact diagnosis based on symptoms may be uncertain (8-10).
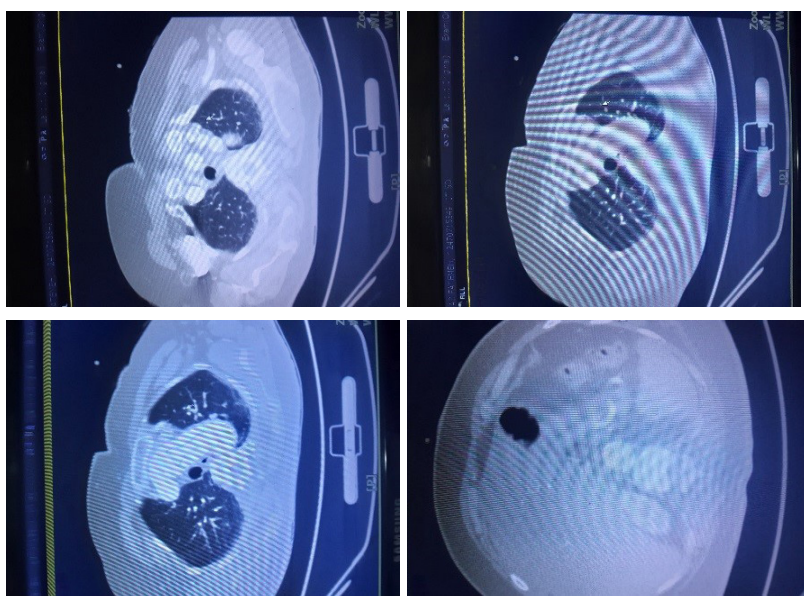

Figure 1. Aortic dissection.

\section{Conclusion}

Our case report has some important points worth considering in terms of physicians' approach to patient management. First, physicians need to consider all parts of history and take a physical examination to come up with an accurate differential diagnosis to prevent maltreatment. Second, in case of a patient with ischemic signs involving multiple vessels without a certain cause, aortic dissection should be considered, especially in patient without the presence of pain as mentioned in our case.

\section{Authors' Contributions}

All authors contributed equally to study design, drafting article, reading critically and accepted finally proof.

\section{Ethical issues}

Ethical concepts of reporting a single patient data is considered and this manuscript does not report any personal information.

\section{Acknowledgements}

We would like to thank the Clinical Research Development Unit of Peymanieh educational and research and therapeutic center of Jahrom University of Medical Sciences for supporting this research.

\section{References}

1. Rosendorff C. Essential Cardiology: Principles and Practice. Humana Pr Inc; 2005.

2. Mészáros I, Mórocz J, Szlávi J, Schmidt J, Tornóci L, Nagy L, et al. Epidemiology and clinicopathology of aortic dissection. Chest 2000; 117(5): 1271-8. doi: 10.1378/ chest.117.5.1271.

3. Von Kodolitsch Y, Schwartz AG, Nienaber CA. Clinical prediction of acute aortic dissection. Arch Intern Med 2000; 160(19): 2977-82. doi: 10.1001/archinte.160.19.2977.

4. Mehta RH, O'Gara PT, Bossone E, Nienaber CA, Myrmel T, Cooper JV, et al. Acute type A aortic dissection in the elderly: clinical characteristics, management, and outcomes in the current era. J Am Coll Cardiol 2002; 40(4): 685-92. 
doi: 10.1016/s0735-1097(02)02005-3.

5. Gawinecka J, Schönrath F, von Eckardstein A. Acute aortic dissection: pathogenesis, risk factors and diagnosis. Swiss Med Wkly 2017; 147: w14489. doi: 10.4414/ smw.2017.14489.

6. Tsai TT, Evangelista A, Nienaber CA, Trimarchi S, Sechtem $\mathrm{U}$, Fattori R, et al. Long-term survival in patients presenting with type A acute aortic dissection: insights from the International Registry of Acute Aortic Dissection (IRAD). Circulation 2006; 114(1 Suppl): I350-6. doi: 10.1161/ circulationaha.105.000497.

7. Jänisch S, Turmanov N, Albrecht UV, Fieguth A, Günther D. [Aortic dissection - a not so rare disease]. Med Klin
(Munich) 2010; 105(12): 871-5. doi: 10.1007/s00063-0101151-2.

8. Young J, Herd AM. Painless acute aortic dissection and rupture presenting as syncope. J Emerg Med 2002; 22(2): 171-4. doi: 10.1016/s0736-4679(01)00459-0.

9. Demircan A, Aksay E, Ergin M, Bildik F, Keles A, Aygencel G. Painless aortic dissection presenting with acute ischaemic stroke and multiple organ failure. Emerg Med Australas 2011; 23(2): 215-6. doi: 10.1111/j.1742-6723.2011.01389.x.

10. Imamura $H$, Sekiguchi $Y$, Iwashita $T$, Dohgomori $H$, Mochizuki K, Aizawa K, et al. Painless acute aortic dissection. - Diagnostic, prognostic and clinical implications. Circ J 2011; 75(1): 59-66. doi: 10.1253/circj.cj-10-0183. 